\title{
Por uma reconstrução teórica do futebol a partir do referencial sociológico de Pierre Bourdieu
}

CDD. 20.ed. 796.05

796.33

http://dx.doi.org/10.1590/1807-55092014000200221

\author{
Juliano de SOUZA* \\ Bárbara Schausteck de ALMEIDA* \\ Wanderley MARCHI JÚNIOR* \\ *Departamento de \\ Educação Física, \\ Universidade Federal \\ do Paraná.
}

\section{Resumo}

Neste artigo temos por objetivo retomar a teoria sociológica de Pierre Bourdieu no sentido de demonstrar alguns dos aspectos em que ela pode ser útil para estudar o futebol no contexto de globalização do espetáculo esportivo, do qual, inclusive, o Brasil se apresenta atualmente como um dos protagonistas por conta, dentre outras coisas, da realização da Copa do Mundo da FIFA em 2014 no país. Na primeira parte do artigo apresentamos então um esboço do quadro teórico de Bourdieu. Em seguida, exploramos algumas situações práticas referentes ao futebol que são passiveis de serem tratadas pelo prisma de seu referencial. Por fim, e a modo de desfecho, reiteramos aqueles pontos em que seu modelo contribui para avançar no tratamento teórico do futebol, especialmente no Brasil.

Palavras-chave: Pierre Bourdieu; Sociologia; Futebol.

\section{Introdução}

A importância social que o futebol vem demonstrando há mais de um século no cenário mundial e, notavelmente, no cenário brasileiro, inspiraram a produção de estudos das mais diferentes disciplinas acadêmicas, o que compreende um raio de circunscrição que abrange investigações que contemplam diversas áreas como, por exemplo, Educação Física, Sociologia, Antropologia, História, Geografia, Administração, Comunicação Social, Economia, dentre outros campos de conhecimento ${ }^{1-2}$.

É oportuno ressaltar que no processo de construção histórica do futebol como um objeto de interesse acadêmico no Brasil, em particular no campo das Ciências Humanas e Sociais, as agendas de pesquisa estão subdivididas basicamente em dois grandes eixos investigativos que, por conseguinte, correspondem a estruturas teórico-metodológicas relativamente distintas, ou seja, com suas especificidades. Essa tipologia sugerida, no entanto, não significa que o exercício de apropriação dessas vertentes teóricas no âmbito dos estudos sobre futebol tenha sido (ou seja) estanque, até porque em várias pesquisas acerca dessa prática esportiva no país é passível de visualizar discussōes sendo edificadas e conduzidas a partir dos apontamentos teóricos sugeridos em ambos os eixos.

Um primeiro eixo estruturante identificado, e com forte influência dos escritos de Gilberto Freyre ${ }^{3}$, abrange aqueles estudos que consistem em aprofundar a relação entre futebol e sociedade brasileira a fim de compreendê-la relacionalmente a partir de questôes que envolvem identidade e o nacionalis$\mathrm{mo}^{4-5}$. Já um segundo eixo, influenciado, sobretudo, pelas ideias de Sérgio Buarque de Holanda ${ }^{3}$, é composto por aqueles estudos que analisam algumas das dinâmicas decorrentes da modernização desse fenômeno no país no tocante às questōes políticas, sociais, econômicas e administrativas. Temáticas em torno da constituição do mercado esportivo, da migração de atletas, da corrupção e da profissionalização da gestão esportiva são alguns exemplos ${ }^{6-8}$.

É importante advertir que os esforços engendrados nesses dois eixos estruturantes dos estudos socioculturais do futebol são louváveis e representam muitos avanços na interpretação deste fenômeno, e do esporte de uma forma geral, no país. Também devemos ressaltar que, a partir dos anos 1990 - e, dentre outras coisas, em função da crescente divulgação dos escritos 
de Pierre Bourdieu (e também de Norbert Elias) no Brasil tratando diretamente do esporte - muitas dessas agendas e arquiteturas teóricas dominantes no referido campo de estudos começaram a ser questionadas, em particular por pleitearem uma versão "sui generis" da circulação do futebol nesta sociedade ou então por consagrarem uma ideia de desvio e atraso do futebol brasileiro em relação ao europeu.

A par desse quadro conjecturado, procuramos neste artigo trazer alguns elementos teórico-práticos que contribuam com um melhor dimensionamento do mesmo, retomando, para tanto, a teoria sociológica de Pierre Bourdieu no sentido de demonstrar alguns dos aspectos em que ela pode ser útil para estudar o futebol no contexto de globalização do espetáculo esportivo. Esse contexto, dentre outras coisas, é particularmente interessante, porque o Brasil se apresenta atualmente como um de seus protagonistas por conta, dentre outras coisas, da realização da Copa do Mundo da FIFA em 2014. Na primeira parte do artigo apresentamos então um esboço do quadro teórico de Bourdieu. Em seguida, e como exercício propedêutico, exploramos algumas situações práticas referentes ao futebol que são passíveis de serem tratadas pelo prisma de seu referencial. Por fim, e a modo de desfecho, reiteramos aqueles pontos em que seu modelo contribui para avançar no tratamento teórico do futebol, especialmente no Brasil.

\section{Um esboço da teoria dos campos de Pierre Bourdieu}

O sociólogo francês Pierre Bourdieu se dedicou ao longo de sua obra a inúmeros domínios de investigação empírica, dentre os quais se incluem a educação, a cultura, a arte, a literatura, o esporte, dentre vários outros objetos. No entanto, nos últimos anos de vida, Bourdieu vinha se dedicando ao estudo dos meios de comunicação, da política e da ordem neoliberal'. Mentor de uma sofisticada teoria das práticas e dos campos, Bourdieu elabora um modelo teórico apto a "[...] identificar os mecanismos sociais que determinam e prescrevem leis de reprodução social" ${ }^{10}$ (p.43). Em outras palavras, o autor procura sistematizar uma teoria que possibilite mapear estratégias ocultas de dominação e rever seus impactos na conservação e reprodução das estruturas de desigualdade social. Ao reforçar e respaldar essa leitura Chartier argumenta que:

Não é justo dizer, nesse sentido, que Bourdieu nunca tratou da possível destruição da reprodução desses mecanismos: é claro que isso faz parte de sua análise, baseada nos mecanismos que asseguram a reprodução da dominação nas condições que permitem, num certo momento histórico dado, uma ruptura com esta dominação ${ }^{11}$ (p.154).

Para fundamentar e colocar em prática esse escopo prescrito ao longo de sua obra, Bourdieu se arma de uma complexa formação conceitual, dentre a qual se destacam os conceitos de dominação simbólica, violência simbólica, poder simbólico, capital simbólico - conceitos inerentes a uma teoria dos sistemas simbólicos - e, finalmente, habitus e campo - que constituem a espinha dorsal de sua teoria e que "[...] são relacionais, no sentido de que só podem funcionar um em relação ao outro"' (p.68).
Segundo CATANI $^{12}$, Bourdieu utiliza pela primeira vez o conceito de "habitus" de forma criteriosa e metódica em seus escritos "A reprodução", de 1970, e "Esboço de uma teoria da prática", de 1972. Posteriormente, essa noção reaparece em seus demais trabalhos, o que permitiu ao autor sistematizar e aperfeiçoar esse conceito operacional ao longo dos anos. Mais especificamente, o esforço de Bourdieu consistiu em recuperar e reinventar o conceito aristotélico de "hexis" utilizado para designar "[...] características do corpo e da alma adquiridas em um processo de aprendizagem" ${ }^{13}$ (p.61). Não obstante esse agenciamento, foi do sentido atribuído nas análises de Erwin Panofsky que Bourdieu imprimiu a reelaboração do conceito de "habitus" segundo uma ótica original e empreendedora ${ }^{11,13}$.

Nessa concepção de "habitus" herdada de Panofsky, Bourdieu, segundo LANDINI ${ }^{14}$, procurava esquivar-se, por um lado, de uma filosofia do sujeito sem, contudo, sacrificar o agente e, por outro lado, de uma filosofia da estrutura sem negar que essa exercesse impacto sobre o agente e através dele. Nas palavras do próprio autor: "[...] os utilizadores da palavra "habitus" se inspiravam numa intenção teórica próxima da minha, que era a de sair da filosofia da consciência sem anular o agente na sua verdade de operador prático de construções de objeto" ${ }^{15}$ (p.62).

Decorre dessa leitura o entendimento de que a noçáo de "habitus" em Bourdieu revela as capacidades criativas e inventivas dos agentes na constituição das práticas e da realidade social. Dessa forma, os sujeitos não são vítimas das estruturas, suporte ou marionetes presos às estruturas sociais. Ao contrário, são ativos no sentido 
que determinam a construção de processos sociais, que, por sua vez, e não numa recíproca relação de causaefeito, podem vir a nortear as práticas dos agentes. Tal como entende MicELI ${ }^{16}$ : "[...] o "habitus" complementa o movimento de interiorização de estruturas exteriores, ao passo que as práticas dos agentes exteriorizam os sistemas de disposiçôes incorporadas" (p.41).

Outra pretensão de Bourdieu ao utilizar o conceito de "habitus" seria romper com a dicotomia indivíduo/ sociedade, explícita na sociologia clássica e ainda em algumas vertentes sociológicas contemporâneas, as quais, sobremodo, orientam e direcionam a análise ora para o indivíduo (agente), ora para a sociedade (estrutura). Em resposta a essas análises fragmentárias, Bourdieu procura compreender e tratar a relação entre indivíduo e sociedade como um processo contínuo de transformação. Para o autor francês, a dimensão individual e cognitiva está tatuada no social. Colocado sob outro aparato conceitual, e em conformidade com o que defende Setton: "[...] pensar a relação entre indivíduo e sociedade com base na categoria de "habitus" implica afirmar que o individual, o pessoal e o subjetivo são simultaneamente sociais e coletivamente orquestrados"13 (p.63).

A definição do próprio conceito reforça essas intenções. De acordo com BourdieU ${ }^{15}$ : "[...] o "habitus" como indica a palavra, é um conhecimento adquirido e também um haver, um capital [...]" (p.61). Em outra oportunidade o autor especifica que:

O habitus é ao mesmo tempo um sistema de esquemas de produção de práticas e um sistema de esquemas de percepção e apreciação de práticas. E, nos dois casos, suas operações exprimem a posição social em que foi construído. Em consequiência, o habitus produz práticas e representações que estão disponíveis para classificação, que são objetivamente diferenciadas; mas elas só são imediatamente percebidas enquanto tal por agentes que possuem o código, os esquemas classificatórios necessários para compreender-lhes o sentido social. Assim, o habitus implica não apenas um sense of one's place, mas também um sense of other's place ${ }^{17}$ (p.158).

Convém reiterar, portanto, que o "habitus" na condição de uma estrutura dinâmica que se apresenta como produto das relações sociais é o que orienta e organiza as mais diversas ações e práticas dos agentes. Ele reporta a um sistema de classificação e, mais que isso, "[...] indica um processo de conformação e orientação da ação, tendendo a assegurar a reprodução dessas relações que o constroem" ${ }^{10}$ (p.54).

Todavia, o conceito de "habitus" em Bourdieu só faz sentido e ganha força teórica e prática quando pensado em relação aos agentes, que na tarefa de portadores, "hospedeiros" do "habitus", se constituem como operadores práticos de construção de objetos de disputa. Sobre a relação entre os agentes sociais e o "habitus", MALERBA ${ }^{18}$ acrescenta que:

[...] o habitus talvez melhor se defina como os limites de ação, das soluções ao alcance do indivíduo em uma determinada situação social concreta. É, portanto, um produto da história que produz práticas individuais e coletivas e que estabelece os limites dentro dos quais os indivíduos são "livres" para optar entre diferentes estratégias de ação (p.216).

É possível afirmar então em conformidade com essa leitura que os "habitus" são tão dinâmicos quanto os agentes que o incorporam. O "habitus" funciona como uma espécie de força que mantém e sustenta determinada ordem social - possibilita compreender os estilos de vida, o conjunto de preferências e gostos dos indivíduos, bem como suas próprias condutas; possibilita mapear a forma como os agentes classificam a si próprios e aos demais indivíduos, servindo, dessa forma, como um inestimável indicador sociológico.

Não obstante a centralidade desse prognóstico no esquema teórico de BOURDIEU ${ }^{19}$, é necessário lembrar que o programa de análise das matrizes comportamentais não pode ser estruturado sem considerar os estímulos externos e objetivos de determinado campo social. Desta forma, para o autor, existe uma cumplicidade ontológica entre o conceito de "habitus" e o conceito de campo, sendo essa última noção definida em seus próprios termos como:

[...] um espaço social estruturado, um campo de for-

ças - há dominantes e dominados, há relações cons-

tantes, permanentes de desigualdade, que se exercem

no interior desse espaço - que é também um campo

de lutas para transformar ou conservar esse campo de

forças. Cada um, no interior desse universo, empenha

em sua concorrência com os outros a força (relativa)

que detém e que define sua posição no campo e, em

conseqüência, suas estratégias (p.57).

Um campo apresenta-se então como espaço de lutas onde os agentes são dotados de armas imprescindíveis para alterar ou manter suas posiçóes, ou seja, as estratégias. Essas últimas, por sua vez, são constituídas e definidas de acordo com a distribuição do capital social, econômico e cultural. Além disso, as forças que aí atuam podem ser antagonistas ou complementares, na medida em que os interesses dos agentes confluem ou divergem. Note-se também que os agentes sociais movimentam-se no interior desse espaço por intermédio de uma aprendizagem 
pré-reflexiva, quer dizer, uma aprendizagem que não é fruto de uma filiação consciente desses atores ao respectivo jogo que estrutura e faz o campo.

Dito de outra maneira, as razões de agir dos agentes não são derivações nem de estímulos racionalistas individuais como tampouco das pressões estruturais do campo. Ao invés disso, estabelece uma complementaridade entre a crença tornada corpo e, portanto, incorporada, e a crença tornada campo, de maneira que a ação social e as práticas sociais resultariam dessa coordenação entre objetivismo e subjetivismo ${ }^{20}$.

Sobre os usos teóricos do conceito de campo é importante ressaltar que o mesmo foi empregado inicialmente por Bourdieu com o intuito de abordar a aplicabilidade do estruturalismo à sociedade francesa. Com o passar do tempo, entretanto, essa noção foi sendo aprimorada e, deste modo, ganhou mais corpo de aplicaçóes como, por exemplo, a cultura e a educação. A ideia de Bourdieu, para sermos mais exatos, era autonomizar as referidas áreas em relação às explicações economicistas ${ }^{11}$.

Ao longo de sua obra, Bourdieu abordou vários campos investigativos: religioso, literário, artístico, político, científico, jornalístico, esportivo, dentre outros. Tal diversidade de objetos remete a uma sofisticada teoria dos campos (ou pluralidade dos mundos, como Bourdieu também chamou), que permite mapear algumas estratégias ocultas de dominação que se inscrevem no interior dos círculos sociais a partir de mecanismos naturalizados de reprodução social. Cabe a ressalva de que tal retomada é feita através de um trato analítico minucioso, rigoroso e que não desqualifica a ação dos agentes.

Nesse sentido, ao se avançar rumo à compreensão dos mecanismos específicos que atuam e formam os diversos campos, é preciso não desconsiderar o raio de ação dos atores. Ao mesmo tempo, e de acordo ainda com o esquema teórico bourdieusiano, para que um pesquisador do mundo social descubra aquilo que está por detrás das ações e das práticas dos agentes sob determinadas condições de concorrência com que esses indivíduos se deparam no campo ${ }^{21}$, é necessário romper com suas primeiras impressões e com as evidências do conhecimento imediato. Tal como assegura BOURDIEU ${ }^{15}$ :

Compreender a génese social de um campo, e aprender aquilo que faz a necessidade específica da crença que o sustenta, do jogo de linguagem que nele se joga, das coisas materiais e simbólicas em jogo que nele se geram, é explicar, tornar necessário, subtrair ao absurdo do arbitrário e do não-motivado os actos dos produtores e as obras por eles produzidas e não, como geralmente se julga, reduzir ou destruir (p.69).

Nesse particular, as ações e tomadas de posiçōes dos atores - produto do encontro entre determinado "habitus" e determinado campo - seriam, na visão teórica de Bourdieu, a chave reveladora para entender a maneira como se reproduz e se mantém, sobremodo, a estrutura que funda a distinção social. Em outras palavras, estas ações ou práticas tal como encaradas pelo autor permitem desvelar, por exemplo, como se constroem objetivamente as diferenças sociais e, por conseguinte, como se consolidam processos de exclusão que resultam das demandas histórico-sociais específicas de um campo e das estratégias de conservação e subversão das posições dos agentes no espaço das tomadas de posição.

Quanto ao entendimento geral dos campos, resta ainda lembrar a possibilidade de campos construídos historicamente como distintos apresentarem mecanismos comuns. Isso permite a Bourdieu melhor formular sua teoria e elaborar conceitos e significados que denotam propriedades universais a essas esferas, muito embora seja necessário advertir que as formas e interesses pelas quais as disputas ocorrem são particulares a cada campo, assim como as disposiçōes dos agentes sociais para agir e, portanto, seus "habitus"22. Por sua vez, essa leitura indica que o que se apreende no estudo, compreensão e interrogação das lutas de um campo, pode, amiúde, ajudar na interpretação das lutas, leis e regras de outro campo e vice-versa. De todo modo, sendo então a análise das especificidades de um campo recomendada e, além disso, com base na proposta de mediação entre agente e estrutura até aqui exposta, convém apresentar uma tentativa de reconstrução teórico-prática do futebol a partir do referencial bourdieusiano.

\section{Pensando o futebol a partir do quadro teórico de Bourdieu}

No exercício de apreensão do futebol a partir dos pressupostos teóricos até aqui elencados, e em conformidade com as sugestōes tecidas por BOURDIEU e WACQUANT ${ }^{22}$, trazemos como primeira observação que o futebol pode ser analisado como um espaço no qual os agentes e estruturas disputam o monopólio dos capitais em jogo, bem como lutam por legitimidade e reconhecimento. Dessa forma, 
as açôes dos agentes, influenciadas pelos seus "habitus", visariam, em última instância, o acúmulo de capitais e também a manutenção de posiçōes de dominância, cujo espectro de possibilidades será problematizado a seguir.

Ainda que essas características supracitadas dêem conta de contextualizar o futebol como espaço de disputas próprio, outra observação teórica se faz pertinente. Ao considerar sua autonomia relativa ou seja, que o processo histórico de constituição da modalidade da forma como se apresenta atualmente segue a lógica de estruturação do campo esportivo, ao mesmo tempo em que diversos traços são exclusivos deste universo e os diferenciam de outras modalidades -, é permissível pensar o futebol como subcampo do campo dos esportes.

De fato, se dimensionarmos o futebol mediante aqueles princípios estruturantes do programa bourdieusiano para Sociologia do Esporte tal como discutido pelo próprio autor ${ }^{23-24} \mathrm{e}$ rediscutido em algumas literaturas da área ${ }^{10,25-29}$, seria interessante tratar do futebol como um subcampo do campo esportivo tendo em vista que essa prática esportiva como as demais seria correspondente a estrutura de um determinado gosto de classe ${ }^{30}$. Daí então a importância de pensar o futebol relacionalmente aos outros esportes, até mesmo para avançar no tratamento de como as práticas esportivas expressariam os "habitus" de classe e as lutas no espaço social mais amplo por prestígio e por reconhecimento.

Não obstante esse uso referenciado e, por assim dizer, mais ortodoxo do esquema de Bourdieu voltado para o domínio de investigação do fenômeno esportivo, é possível também retomar o futebol como um campo relativamente autônomo com relação ao espaço social estruturado em torno dos esportes. É a esse segundo uso teórico, inclusive, que nos remetemos na continuidade do artigo por entender, em primeiro lugar, que o futebol na condição de um esporte de apelo massivo, distribuído entre as diferentes classes sociais e que ocupa um lugar de destaque na hierarquia de oferta e consumo dos bens esportivos e culturais na sociedade moderna, demanda de um tratamento teórico à parte e como campo relativamente à parte. Em segundo lugar, e com o respaldo na noção de campo como forma de olhar as relaçóes sociais ${ }^{15,31}$, entendemos que as maiores contribuições do modelo de Bourdieu para o estudo do futebol se tornam mais evidentes quando pensamos nessa prática como um locus propriamente específico.

Avançando nessa proposta de tratamento, compete ressaltar que o futebol visto e contemplado como um campo relativamente autônomo tanto sofre a influência de diversos campos em determinados aspectos estruturais de funcionamento, quanto mantêm um grau manifesto de autonomia em relação a outros aspectos. Nesse caso, para realizar o primeiro passo da análise de um campo social - a leitura de um microcosmo específico frente ao campo do poder, aqui entendido como espaço de relações de força estabelecido em razão da posse e do volume dos capitais aptos a separar e definir quem são as classes dominantes e, por conseguinte, quem são as classes dominadas ${ }^{15,20,32}$ - há também a necessidade de interpretá-lo numa relação de contraste e ênfase perante outros campos, visto que o espaço social é composto por todos esses microcosmos que tendem a reproduzir a estrutura do campo do poder em suas lógicas internas.

No bojo desse inventário, outro ponto que não pode ser negligenciado é a posição que o futebol, na condição de prática esportiva hegemônica, ocupa nas manifestaçôes de lazer e no contexto da Educação Física escolar no Brasil. Além disso, e quanto à posição do campo futebolístico frente ao campo do poder, é passível de se assumir o raciocínio de que o mesmo se apresenta como dominante no universo de consumo dos bens culturais e, mais que isso, com posição de relativo destaque e dominância no contexto do espetáculo esportivo globalizado ${ }^{6}$, condição que, por sua vez, tende a ser mais bem delineada ao retomarmos as disposiçōes dos agentes sociais protagonistas na construção da história do futebol moderno, o papel das estruturas responsáveis pela gestão do futebol e pela sua progressiva transformação em esporte-espetáculo.

Um segundo passo para análise do campo futebolístico, com base no referencial teórico de Bourdieu seria o estabelecimento de um mapa contendo as estruturas objetivas bem como as relaçōes entre os agentes e instituiçóes ${ }^{22}$ atuantes no contexto do futebol profissional orientado por dimensões altamente mercantis e espetaculares que, por sua vez, tendem a nortear as relaçôes sociais no domínio do esporte escolar, de lazer, amador etc. Entre esses agentes e estruturas mencionadas atuantes no campo futebolístico, destacam-se aquelas instituições que formam uma hierarquia de poder que concorre para manutenção dos interesses respectivos da Federação Internacional de Futebol Associado (FIFA), de suas confederações continentais filiadas, das confederações e federações nacionais, dos clubes profissionais e dos centros formadores de atletas.

Imperativo notarmos que a existência dessas estruturas aponta para um quadro de disputas em que a dominação, a princípio, estaria impressa na própria relação hierárquica, na qual os dominantes 
tenderiam a agir para manterem suas posiçóes e os dominados para ascenderem nesse campo de forças. Além disso, as tentativas de mudança nesse quadro não se dão tão somente por meio de estratégias de transformações funcionais, isto é, em função do alcance espacial que essas instituições possuem, mas essencialmente se justificam no acúmulo e volume dos capitais econômico e simbólico em relação às instituições pares (a exemplo das confederaçōes continentais, das confederações e federações nacionais), num jogo onde essas entidades, dentre outras coisas, buscam a notoriedade dos seus membros executivos, em especial de seus presidentes, para pleitearem cargos de maior destaque nas instituiçōes hierarquicamente superiores. Esses casos são exemplarmente visíveis para as eleições de países-sede para a Copa do Mundo e para o cargo de presidente da FIFA.

$\mathrm{Na}$ esteira dessa análise, é importante frisar que a FIFA é uma instituição que se autodenomina e é objetivamente reconhecida como responsável pela administração e pelo gerenciamento do futebol no mundo. Organização internacional não-governamental, assim como outras instituições que gerem o esporte no âmbito internacional ${ }^{33}$, a FIFA possui 208 federaçōes nacionais filiadas, incluindo países que não conquistaram sua independência em casos específicos $^{34}$. Essa perspectiva "inclusiva", por sua vez, pode ser entendida como parte da visão institucional da FIFA em expandir o mercado futebolista e se fazer presença máxima em todo o mundo.

Ao lado dessas situações arroladas, destaca-se também a retórica oficial da FIFA em supostamente não se envolver em questões políticas, guerras ou em outras disputas entre países. Um exemplo que corrobora essa lógica naturalizada pela qual a FIFA se apresenta como uma instituição "messiânica" e "pacificadora" se visualiza no amistoso da seleção brasileira de futebol contra a seleção do Zimbábue, possivelmente financiado pelo ditador Robert $\mathrm{Mu}$ gabe numa estratégia de autopromoção antes da Copa do Mundo de 2010 na África do Sul. Apesar das críticas por parte da imprensa, o presidente da FIFA Joseph Blatter "ignorou" as questões políticas ao dar sua opinião sobre o evento: "O que eu vi na televisão, foi o entusiasmo das pessoas, conectados com o futebol. Eu achei que foi uma boa ideia ir lá e jogar futebol pelo povo do país [sic!]"35.

Em que pese, no entanto, tais retóricas, essa busca por plena autonomia, isenção e neutralidade por parte da FIFA assim como sua "política evangelizadora" são bastante discutíveis, tendo em vista, dentre outras coisas, a imposição de normativas reguladoras pelos
Estados ou pela União Européia no caso da Euro$\mathrm{pa}^{36-37}$, como pela dependência de incentivos políticos e econômicos na promoção de seus eventos, principalmente nos diferentes torneios internacionais e nas Copas do Mundo. Além disso, é necessário advertir que a FIFA tende a impor aos países-sedes de seus eventos (ou que então almejam sediá-los) uma série de obrigaçóes pontuais e de acordos contratuais que acabam se sobrepondo objetivamente aos interesses políticos e econômicos locais, a ponto, muitas vezes, de os subverterem. Esses arranjos, por conseguinte, podem ser mais bem delineados ao nos reportamos ao caso da Copa do Mundo de Futebol que será realizada no Brasil neste ano de 2014. É oportuno, inclusive, salientar que nos procedimentos para realização deste evento, a FIFA fez uma série de exigências especiais para a competição, tais como operações livres de taxação e tributos, maior abertura nos processos de entrada e saída de pessoas do país, etc ${ }^{38}$.

$\mathrm{Na}$ construção deste cenário, cabe agregar o comentário de que a escolha do Brasil como sede de tal evento proporcionou e tem proporcionado atenção midiática e retornos simbólicos às principais entidades envolvidas no processo, isto é, a FIFA, a Confederação Brasileira de Futebol (CBF) e o governo brasileiro. Embora sem o mesmo entusiasmo da "conquista" frente a uma disputa internacional mais evidente, como seria a eleição do Rio de Janeiro como sede dos Jogos Olímpicos de 2016 dois anos mais tarde ${ }^{39}$, a escolha do Brasil como sede da Copa do Mundo da FIFA em 2007 veio acompanhada da promessa de construção de estádios financiados pela iniciativa privada e da retórica de impactos na economia e turismo, além da crença na possibilidade ímpar do país expressar o seu crescimento econômico e dos agentes demonstrarem sua capacidade de realização de grandes projetos ${ }^{40-43}$. O fato, no entanto, do processo de preparação ter apontado para um panorama distinto daquele esboçado em 2007, para além das razóes econômicas e gerenciais de planejamento, requer a consideração de outros elementos analíticos.

Ainda no tocante ao desvelamento do papel da FIFA no contexto de conformação do esporteespetáculo, é necessário reiterar que a mesma, a exemplo também do Comitê Olímpico Internacional (COI), trata-se de uma instituição que conserva uma posição de destaque no espaço social por ter o monopólio de um produto que, em seus principais eventos, concentram apelo popular, atenção midiática e significância internacional. Nunca é demais insistir que a importância simbólica do esporte, e especificamente do futebol, alavancada por uma 
série de características inerentes no processo de produção, difusão e consumo dos megaeventos ${ }^{44}$ gera inúmeras mudanças nas regulaçôes nacionais e internacionais que entidades e governos (que possuem o interesse em fazer parte desse sistema) são obrigados a cumprir. Daí a possibilidade de estudar o futebol profissional como um espaço onde suas instituições mantenedoras, em particular a FIFA e suas parceiras institucionais, se valem, ainda que de forma não plenamente racionalizada, de uma prática com valores simbólicos e emocionais cristalizados no espaço social, para neutralizar ou subverter as tomadas de posiçôes dos agentes de outros campos.

Em outras palavras, as análises sugeridas integrariam, mais especificamente, um programa investigativo no qual as tomadas de posição e os raios de ação da FIFA fossem compreendidos juntamente com o "habitus" de seus dirigentes. Sem a pretensão de esgotar essa abordagem, é possível conjecturar com base na literatura que o "habitus" dos agentes à frente da FIFA - e, portanto, a visão de mundo da qual essa instituição se faz defensora, para além do romantismo ingênuo fundado na teoria do "fair play" e do esporte pelo esporte, de forma semelhante a outras organizaçōes esportivas - sugere um alinhamento aristocrático, por vezes não democrático, de relacionamento íntimo com regimes ditatoriais e com grandes corporações multinacionais, além de uma frequente suspeita de casos de corrupção ou do não cumprimento de suas próprias regulamentações éticas ${ }^{33,45-49}$.

Resguardadas as devidas particularidades, análises semelhantes a essas descritas para o caso da FIFA são passíveis de serem estendidas para pensar suas confederações continentais filiadas: Confederação Asiática de Futebol (AFC), Confederação Africana de Futebol (CAF), Confederação da América do Norte, Central e Caribe (CONCACAF), Confederação Sulamericana de Futebol (CONMEBOL), Confederação de Futebol da Oceania (OFC) e, por fim, a União das Associações Européias de Futebol (UEFA). Tais confederaçôes continentais organizam torneios locais entre clubes e seleçôes, aproximando as federações nacionais do poder de regulação exercido pela FIFA ${ }^{50}$.

Cabe destacar que muito embora essa atuação seja dividida geograficamente, uma série de disputas de poder se protagoniza entre essas confederaçōes, em especial quando se tratam de votações acerca de assuntos referentes às demandas internas ou das eleiçôes para presidente da FIFA, em que cada federação nacional teria objetivamente o mesmo peso para voto. Dessa forma, embora a UEFA represente 53 federaçôes com seleçôes e equipes de grande capital econômico e simbólico pelos títulos acumulados, ela tem um potencial de voto que do ponto de vista numérico está abaixo, por exemplo, da CAF, que com 54 federaçôes atuantes, possui representatividade econômica e simbólica inferior a UEFA.

No âmago dessa lógica, muitas propostas que partem do presidente da FIFA ou de potenciais candidatos a essa posição para a gestão do futebol mundial inevitavelmente contam com critérios políticos que têm por objetivo agradar o máximo de confederações continentais, com especial atenção para medidas que beneficiem a África e diminuam as defasagens financeiras em relação a outras regiōes ${ }^{51}$. Nesse particular, embora tais propostas, assim como a estrutura de "rodízio" dos continentes que sediariam as Copas do Mundo da FIFA 2010/2014, sejam superficialmente justificadas nesses discursos de "democracia geográfica", um olhar mais atento às disputas do campo futebolístico aponta para justificativas menos naturalizadas e ingênuas.

É imprescindível também somar a compreensão desse jogo político conjecturado a partir de algumas lógicas práticas, as denúncias de corrupção direcionadas ao presidente da AFC, Mohamed Bin Hamman, do Catar, que foi afastado da sua posição pouco tempo após se posicionar como concorrente de Joseph Blatter às eleiçôes presidenciais da FIFA em 2011. Por sinal, e nesse mesmo período, outro dirigente afastado foi Jack Warner, então presidente da CONCACAF. Além desses casos, denúncias também foram direcionadas ao presidente da CONMEBOL, Nicolas Leoz entre outros dirigentes do futebol na América do Sul, incluindo o ex-presidente da CBF, Ricardo Teixeira ${ }^{52}$.

Respaldados nessas lógicas apontadas, é importante destacar, até mesmo como um princípio metodológico geral para subsidiar discussões futuras sobre a conformação dessas redes estratégicas de corrupção no futebol mundial, que à medida que o escalonamento analítico vai se circunscrevendo mais à escala micro ou, em termos mais apropriados, vai se estendendo e se desdobrando da dimensão global para as dimensões nacionais e dessas últimas para as regionais e clubísticas -, outros elementos analíticos insurgem, mas que, em essência, mantêm conexôes íntimas com as lógicas que regem, estruturam e conformam o quadro macrossocial de gestão do futebol moderno em seu formato profissional e em suas dimensōes mercantis e espetacularizadas, tais como aqui brevemente conjecturamos.

Um exemplo disso que estamos dizendo pode ser perspectivado numa análise mais situada e circunstanciada dos arranjos recentes que envolveram 
a negociação das relações de poder na CBF e que culminaram então com a renúncia de Ricardo Teixeira ao posto de presidente dessa instituição. A propósito, uma reportagem feita pela revista Piauí com Ricardo Teixeira e intitulada "O presidente" expôs um ponto de vista pouco comentado sobre a vida política do ex-presidente, sobre seus posicionamentos soberanos, por vezes desrespeitosos, e sua rotina luxuosa, que refletem, em parte, a forma como a CBF e o futebol brasileiro foram organizados (e ainda há resquícios disso) de acordo com o "habitus", posições e interesses desse agente social, de seus aliados e de outros dirigentes.

Essa reportagem, por sua vez, acabou gerando uma comoção revoltosa nas redes sociais de interação virtual, muito embora seja necessário advertir que uma insatisfação semelhante tem sido apontada em alguns argumentos críticos direcionados ao atual presidente da CBF e do Comitê Organizador Local da Copa de 2014 (COL), a saber, José Maria Marin, cujo histórico de envolvimento com a Ditadura
Militar no Brasil é motivo que mobiliza pessoas como o jornalista Juca Kfouri e o deputado federal e ex-jogador de futebol Romário a solicitarem em petição sua saída do cargo ${ }^{54}$.

Enfim, essas dentre outras situações práticas que se estendem da escala global à local, que permeiam o micro e o macro e que, acima de tudo, são devedoras à soma e à negociação de lógicas que perpassam o campo futebolístico, o campo político e o campo econômico, não necessariamente nessa ordem, são férteis no sentido de ilustrar o quão articulado é o jogo das relações, que de um ponto de vista histórico, mas também estrutural, concorreram para que o futebol se tornasse um fenômeno espetacularizado de dimensão global e, mais que isso, emergisse como um campo relativamente autônomo. Na sequência, passamos à última seção do artigo e apontamos, com base nas discussões até aqui reunidas, quais são as contribuições potenciais do modelo de Bourdieu para os estudos do futebol e, em particular, para se repensar o futebol brasileiro.

\section{A modo de desfecho: Bourdieu e o os estudos do futebol}

O campo da Sociologia do Esporte e, mais especificamente, o campo dos estudos socioculturais do futebol tiveram um crescimento expressivo nessas duas últimas décadas no Brasil, conforme diagnosticado e sugerido por diversos autores nas mais diferentes terminologias possíveis ${ }^{1-2,55-61}$. Esse crescimento refletido tanto em termos numéricos de produção das pesquisas, como na qualidade dos trabalhos e, principalmente, na maior abertura dos periódicos científicos a esses tipos de estudos, é animador e promissor, não obstante, ainda existam alguns problemas a serem enfrentados pela Sociologia do Esporte e, em especial, pelos estudos socioculturais do futebol.

Um dos problemas que essas áreas ainda precisam discutir se refere basicamente ao critério de seleção dos referenciais teóricos para subsidiar a leitura dos objetos empíricos. Mais precisamente, nos referimos ao fato de as teorias ainda serem eleitas arbitrariamente ou segundo as predileçôes pessoais dos autores para subsidiar a compreensão e explicação da realidade social na qual está evidentemente incluída a estrutura dos fatos e processos esportivos. Quando então argumentamos ao longo do artigo que o referencial de Bourdieu expresso em sua teoria dos campos é útil para pensar o futebol a partir de uma perspectiva de reconstrução estrutural da conformação dessa prática como um espaço de disputas relativamente autônomo, estamos atentos ao fato de que sua teoria, como qualquer outra, apresenta limites e não pode ser generalizada, sem um esforço de retradução teórica, para pensar os mais variados objetos de pesquisa, sejam eles referentes ao esporte ou não.

Quanto aos eventuais limites da teoria de Bourdieu para o estudo sociológico do futebol, compete dizer que seu modelo, no nosso ponto de vista, não ajuda a explicar a distribuição do futebol entre as diferentes classes e grupos a ponto de se tornar um esporte de conotação massiva senão em quase todos os países ocidentais, ao menos em boa parte deles. Além disso, o seu quadro teórico não permite dar conta daquelas propriedades intrínsecas às relações que os agentes e grupos constituiram no futebol e que foram ingredientes essenciais para que o mesmo, desde que submetido a uma lógica de oferta e demanda, pudesse se difundir para todas as direções sociais e a partir dos mais diferentes usos. Sem dúvida, são aspectos que mereceriam uma discussão mais pormenorizada, o que, no entanto, fugiria ao escopo original do artigo e demandaria um espaço excessivo e, portanto, um tratamento teórico à parte.

Já no tocante ao desvelamento daquelas contribuições do referencial sociológico de Bourdieu que 
julgamos indispensáveis para se estudar o futebol, independentemente das relativas particularidades que determinadas sociedades apresentam em relação a outras, é passível de concluir, em conformidade com a discussão teórica desenvolvida nas páginas anteriores, que seu modelo permite pensar e explicar o modo com que as visões de mundo institucionais da FIFA e de suas parceiras institucionais ajudaram a conformar o futebol profissional na condição de esporte-espetáculo e como produto globalizado a partir de uma lógica dialética firmada mutuamente entre agentes e estruturas.

Evidentemente que uma visualização mais precisa, sistemática e abrangente dessas possibilidades explicativas que se abrem a partir do referencial de Bourdieu, necessitaria de uma incursão empírica muito mais ampla e rigorosa da que oferecemos neste artigo. Em que pese, no entanto, as reticências que esse quadro denota, acreditamos ter reunido uma série de evidências empíricas que demonstram que o futebol, seja a nível global ou local, tem se construído como um espaço de disputas no qual se identifica uma rígida hierarquia de poder onde acabam prevalecendo os interesses da FIFA e das instituições sob sua tutela. Reunimos também nesse percurso de reconstrução do futebol como um campo autônomo, alguns elementos que nos permitem afirmar a existência de um "capital futebolístico" pelo qual a FIFA tem feito seus interesses se sobreporem aos interesses de outros atores.

Como última observação a ser tecida, e em termos de reforço daqueles aspectos que a teoria de Bourdieu pode ser útil para se repensar o futebol no Brasil, convêm frisar que se a Sociologia Reflexiva e a metateoria que lhe sustenta fornece aos estudiosos do esporte uma série de ferramentas metodológicas que, somadas ao exercício obsessivo de vigilância epistemológica, permite-lhes romper com as aparências imediatas do mundo social, com o senso comum e com as prenoções camufladas sob a forma de bom senso científico ou senso-douto ${ }^{29}$. Além disso, a teoria dos campos como modelo heurístico da Sociologia Reflexiva de Bourdieu, possibilita, no tocante aos estudos do futebol, realizar uma ruptura com as ideias muito difundidas acerca de uma versão sui generis de futebol brasileiro ou então de desvio e atraso do futebol nacional com relação ao europeu.

Esse tipo de retomada, por sua vez, se torna possível à medida que: 1) as discussões teóricas sobre os aspectos simbólico-emocionais do futebol brasileiro deixam de afirmar a identidade nacional; 2) a abordagem dos processos políticos e mercadológicos do futebol brasileiro não mais instila análises que idealizam uma modernização do futebol brasileiro à luz da "modernidade-normativa" do futebol europeu; 3) as tramas de corrupção do futebol brasileiro deixam de ser explicadas como se a corrupção fosse uma característica estrutural desta sociedade ou como se as relações personalistas pautadas em trocas de favores se limitassem a alguns tipos de sociedades tidas como pré-modernas, arcaicas, tradicionais e, ao invés disso, não insurgisse como atributo do qual todos os tipos de formação social de ontem e de hoje, do centro e da periferia do capitalismo, partilham, tal como podemos argumentar com respaldo na obra do sociólogo Jessé Souza ${ }^{62-65}$.

Em resposta a essas ideias que acabam se fazendo presentes tanto no âmbito dos estudos socioculturais do futebol brasileiro como também na esfera do senso comum e do debate público nacional, o modelo teórico de Bourdieu expresso, em particular, naqueles desdobramentos que imputamos ao mesmo do decorrer do artigo, fornece um instrumental de análise acerca da realidade futebolística brasileira pelo qual é permitido demonstrar de modo insofismável que existe uma articulação de interesses somada a um agir estratégico permeando o campo futebolístico numa escala que vai do global ao local de maneira que as diferenças de funcionamento desse microcosmo mediante as variáveis nacionais próprias a cada sociedade seriam mínimas ou evocadas para legitimar sistemas de crenças.

Nesse sentido, é possível afirmar a partir do referencial teórico de Bourdieu que a corrupção no futebol não é uma característica essencial de uma sociedade ou de outra e, ao invés disso, uma estratégia recorrente no campo futebolístico seja no contexto da sociedade brasileira, inglesa ou francesa, dentre outras. Já no tocante à modernização do futebol, o modelo bourdieusiano ao demonstrar que a modernidade é marcada pelo surgimento de campos relativamente autônomos com leis de funcionamento invariantes e, portanto, que as ideias e práticas modernas estão vinculadas ao mercado, permite supor que, em essência, as relaçóes sociais construídas no futebol brasileiro e sul-americano não são tão diferentes daquelas que permeiam o futebol europeu, africano ou asiático.

Por fim, pelo prisma do modelo teórico de Bourdieu é possível também tratar das questōes simbólicas que orientam a circulação da prática futebolística na modernidade, sem desembocar, no entanto, naquelas análises influenciadas por toda espécie de vínculos emocionais regionalistas ou nacionalistas e, de forma contrária a essas propostas analíticas, 
demonstrando que o "capital futebolístico" atuante no Brasil, na Espanha ou no Japão, para evocarmos três sociedades de regióes diferentes do mundo, acaba sendo ou fazendo as vezes de uma "moeda simbólica" ou, melhor dizendo, de capital simbólico que a FIFA, suas entidades adjacentes, os governos e os grupos empresariais, se usufruem, nas formas específicas que lhes competem, a fim de obter vantagens de diversas ordens no jogo social e conferir uma condição de prestígio e reconhecimento a eles próprios.

\begin{abstract}
For a theoretical reconstruction of football through the sociological reference of Pierre Bourdieu

This article aims to review the sociological theory of Pierre Bourdieu to present some of its possibilities to study the football in the context of sport spectacle globalization, in which Brazil is currently on of its protagonists as host of the 2014 FIFA World Cup, among other reasons. In the first part of this article, we present an outline of the theoretical framework of Bourdieu. Then, we explore some empirical recent cases in football that are suitable to analysis through his referential. Finally, to conclude, we reinforce the possibilities of his model to advance in the theoretical analysis of football, especially in Brazil.
\end{abstract}

KEY WORDS: Pierre Bourdieu; Sociology; Football.

\title{
Referências
}

1. Gastaldo E. Estudos sociais do esporte: vicissitudes e possibilidades de um campo em formação. Logos 2010;17:6-15.

2. Gastaldo E. Comunicação e esporte: explorando encruzilhadas, saltando cercas. Comun. Midia Consumo. 2011;8:39-51.

3. Wisnik JM. Veneno remédio: o futebol e o Brasil. São Paulo: Companhia das Letras; 2008.

4. Helal R. Idolatria e malandragem: a cultura brasileira na biografia de Romário. In: Alabarces P, organizador. Futbologias: fútbol, identidad y violência en América Latina. Buenos Aires: CLACSO; 2003. p.225-40.

5. Soares AJ. Futebol brasileiro e sociedade: a interpretação culturalista de Gilberto Freyre. In: Alabarces, P, organizador. Futbologias: fútbol, identidad y violência en América Latina. Buenos Aires: CLACSO; 2003. p.145-62.

6. Proni MW. Esporte-espetáculo e futebol-empresa [tese]. Campinas (SP): Universidade Estadual de Campinas; 1998.

7. Rodrigues FXF. Modernidade, disciplina e futebol: uma análise sociológica da produção social do jogador de futebol no Brasil. Sociologias. 2004;11:260-99.

8. Ribeiro LC, organizador. Futebol e globalização. Jundiaí: Fontoura; 2007.

9. Loyola MA. “Bourdieu e a Sociologia”. In: Bourdieu P. Pierre Bourdieu entrevistado por Maria Andréa Loyola. Rio de Janeiro: UERJ; 2002. p.68-83.

10. Marchi Júnior, W. “Sacando” o foleibol. São Paulo: Hucitec; 2004.

11. Chartier R. Bourdieu e a história: debate com José Sérgio Leite Lopez. Topoi. 2002;3:139-82.

12. Catani AM. A sociologia de Pierre Bourdieu (ou como um autor se torna indispensável ao nosso regime de leituras). Educ Soc. 2002;23:57-75.

13. Setton MGJ. A teoria do habitus em Pierre Bourdieu: uma leitura contemporânea. Rev Bras Educ. 2002;20:60-70.

14. Landini T. Jogos habituais: sobre a noção de habitus em Pierre Bourdieu e Norbert Elias. X Simpósio Internacional Processo Civilizador; 2007; Campinas, BR. Campinas: UNICAMP; 2007.

15. Bourdieu P.. O poder simbólico. Lisboa: Difel; 1989.

16. Miceli S. A força do sentido. In: Bourdieu P. A economia das trocas simbólicas. São Paulo: Perspectiva; 1998, p.vii-lxi.

17. Bourdieu P. Coisas ditas. São Paulo: Brasiliense; 1990.

18. Malerba J. Para uma teoria simbólica: conexōes entre Elias e Bourdieu. In: Cardoso CF, Malerba J, organizadores. Representações: contribuição a um debate transdisciplinar. Campinas: Papirus; 2000. p.199-225.

19. Bourdieu P. Sobre a televisão. Rio de Janeiro: Zahar; 1997. 
20. Bourdieu P. O senso prático. Petrópolis: Vozes; 2009.

21. Wacquant L. Hacia una praxeología social: la estructura y la lógica de la sociología de Bourdieu. In: Bourdieu P, Wacquant L. Una invitación a la sociología reflexiva. Buenos Aires: Siglo XXI; 2005. p.25-90.

22. Bourdieu P, Wacquant L. Una invitación a la sociología reflexiva. Buenos Aires: Siglo XXI; 2005.

23. Bourdieu P. Como é possível ser esportivo? In: Bourdieu P. Questões de sociologia. Rio de Janeiro: Marco Zero; 1983. p.136-53.

24. Bourdieu P. Programa para uma sociologia do esporte. In: Bourdieu P. Coisas ditas. São Paulo: Brasiliense; 1990. p.207-20.

25. Marchi Júnior W. Bourdieu e a teoria do campo esportivo. In: Proni MW, Lucena RF, organizadores. Esporte: história e sociedade. Campinas: Autores Associados; 2002. p.77-111.

26. Rodrigues FXF. Pierre Bourdieu: esquema analítico e contribuição para uma teoria do conhecimento na sociologia do esporte. Soc Cult. 2005;1:111-25.

27. Azevedo A. Bourdieu e o futebol: uma interpretação do sucesso profissional de jogadores e técnicos. XIII Congresso da Sociedade Brasileira de Sociologia; 2007; Recife, BR. Recife: Universidade Federal de Pernambuco; 2007.

28. Souza J, Marchi Júnior W. Por uma sociologia reflexiva do esporte: consideraçóes teórico-metodológicas a partir da obra de Pierre Bourdieu. Movimento (Porto Alegre). 2010;16:293-315.

29. Souza J. A reflexividade metodológica de Pierre Bourdieu como modelo heurístico para leitura do esporte no Brasil: pontencialidade e contribuições. In: Marchi Júnior W, organizador. Ensaios em sociologia do esporte. São Paulo: Factash; 2011. p.29-53.

30. Bourdieu P. A distinção: crítica social do julgamento. São Paulo: EDUSP; 2008.

31. Passeron J-C. Morte de um amigo, fim de um pensador. In: Encrevé P, Lagravé R-M, organizadores. Trabalhar com Bourdieu. Rio de Janeiro: Bertrand Brasil; 2005. p.17-91.

32. Bourdieu P. Meditações pascalianas. Rio de Janeiro: Bertrand Brasil; 2001.

33. Sugden J, Tomlinson A. FIFA and the contest for world football: who rules the people's game? Cambridge: Polity; 1998.

34. FIFA. Federação Internacional de Futebol. FIFA Statues. [citado 4 ago. 2011]. Disponível em: http://www.fifa.com/ $\mathrm{mm} /$ document/affederation/generic/01/48/60/05/fifastatuten2011_e.pdf.

35. Paiva C. Blatter faz elogios ao polêmico amistoso Brasil x Zimbábue. Terra. 7 jun. 2010. [citado 4 ago. 2011]. Disponível em: http://esportes.terra.com.br/futebol/copa/2010/noticias/0,,OI4476641-EI15647,00-Blatter+faz+elogios+a $\mathrm{o}+$ polemico+amistoso+Brasil+x+Zimbabue.html.

36. Parrish R. Football's place in the single European market. Soccer Soc. 2002;3:1-21.

37. Garcia B. UEFA and the European Union: from confrontation to co-operation? J Contemp Eur Res. 2007;3:202-23.

38. FIFA exige dez garantias do governo brasileiro até julho. Gazeta do Povo. 22 abr. 2007. [citado 4 ago. 2011]. Disponível em: http://www.gazetadopovo.com.br/esportes/conteudo.phtml?id=655122.

39. Damo AS. O desejo, o direito e o dever: a trama que trouxe a Copa ao Brasil. Movimento (Porto Alegre). 2012;18:41-81.

40. Brasil é confirmado como sede da Copa do Mundo de 2014. Estadão. 30 out. 2007. [citado 8 mar. 2012]. Disponível em: http://www.estadao.com.br/noticias/esportes,brasil-e-confirmado-como-sede-da-copa-do-mundo-de-2014,72847,0.htm.

41. Apresentação brasileira fala em benefícios; Blatter se diz “impressionado”. Folha de S. Paulo. 30 out. 2007. [citado 8 mar. 2012]. Disponível em: http://www1.folha.uol.com.br/folha/esporte/ult92u341023.shtml.

42. Lula quer que Copa-2014 mostre crescimento econômico do Brasil. Folha de S. Paulo. 30 out. 2007. [citado 8 mar. 2012]. Disponível em: http://www1.folha.uol.com.br/folha/esporte/ult92u341088.shtml.

43. Oficial! A Copa do Mundo é nossa. Globoesporte. 30 out. 2007. [citado 8 mar. 2012]. Disponível em: http://globoesporte.globo.com/ESP/Noticia/Futebol/Campeonatos/0,,MUL163196-9790,00.html.

44. Roche M. Mega-events and modernity: olympics and expos in the growth of global culture. London: Routledge; 2000.

45. Simson V, Jennings A. Os senhores dos anéis: poder, dinheiro e drogas nas Olimpíadas modernas. São Paulo: Nova Cultural/Best Seller; 1992.

46. BBC Panorama. The beautiful bung: corruption and the world cup. BBC One. 11 jun. 2006. [cited 2011 ago. 4]. Available from: http://news.bbc.co.uk/2/hi/programmes/panorama/5076282.stm.

47. BBC Panorama. FIFA’s dirty secrets. BBC One. 29 nov. 2010. [cited 2011 ago. 4]. Available from: http://www.bbc. co.uk/programmes/b00wfl8t.

48. Jennings, A. Jogo sujo: o mundo secreto da FIFA. São Paulo: Panda Books, 2011.

49. English media angry at Fifa World Cup voting 'fix'. BBC Sport. 3 dez. 2010. [cited 2011 ago. 4]. Available from: http://news.bbc.co.uk/sport2/hi/football/9253692.stm.

50. FIFA. Federação Internacional de Futebol. Confederações. [citado 4 ago. 2011. Disponível em: http://pt.fifa.com/ aboutfifa/organisation/confederations/index.html. 
51. Sugden J, Tomlinson A, Darby P. FIFA versus UEFA in the struggle for the control of world football. In: Brown A, editor. Fanatics! Power, identity and fandom in football. London: Routledge; 2002.

52. Rodrigues JL. Mohammed bin Hammam, Jack Warner e mais dois membros são afastados pelo Comitê de Ética da Fifa. O Globo. 29 mai. 2011. [citado 4 ago. 2011]. Disponível em: http://oglobo.globo.com/esportes/mat/2011/05/29/ mohammed-bin-hammam-jack-warner-mais-dois-membros-sao-afastados-pelo-comite-de-etica-da-fifa-924558151. asp\#ixzz1U6nm0Pn9.

53. Pinheiro D. O presidente. Revista Piauí. jul. 2011. [citado 4 ago. 2011]. Disponível em: http://revistapiaui.estadao.com.br/edicao-58/figuras-do-futebol/o-presidente?utm_source=revistapiaui\&utm_campaign=share\&utm_medium=facebook\&utm_ content=http $\% 3 \mathrm{~A} \% 2 \mathrm{~F} \% 2$ Frevistapiaui.estadao.com.br\%2Fedicao- $58 \% 2 \mathrm{Ffiguras}-$ do-futebol\%2Fo-presidente.

54. Kfouri J. Entregues as 47 cópias da petição "Fora Marin!”. Blog do Juca Kfouri, UOL Esportes. 5 abr. 2013. [citado 15 abr. 2013]. Disponível em: http://blogdojuca.uol.com.br/2013/04/entregues-as-47-copias-da-peticao-fora-marin/.

55. Freitas CMSM, Costa AS. Gênese da sociologia do desporto: evolução histórica. Mneme: Rev Humanidades. 2006;8:6-23.

56. Marchi Júnior W, Cavichiolli FR. Diagnóstico da sociologia do esporte no Brasil: para a consolidação de um campo do conhecimento. In: Cornejo M, Marchi Júnior W, organizadores. Estudios y proyectos en sociología del deporte en América Latina. Chile: ALESDE; 2008. p.102-12.

57. Medeiros CCC, Godoy L. As referências de Pierre Bourdieu e Norbert Elias na Revista Brasileira de Ciências do Esporte: mapeando tendências de apropriação e de produção de conhecimento na área da Educação Física (1979-2007). Rev Bras Ciênc Esporte. 2009;30:199-214.

58. Ferreira AL. O estado da arte da sociologia do esporte no Brasil: um mapeamento da produção bibliográfica de 1997 a 2007 [dissertação]. Curitiba (PR): Universidade Federal do Paraná; 2009.

59. Ferreira AL. Mapeamento da produção científica sobre a sociologia do esporte no Brasil. In: Marchi Júnior W, organizador. Ensaios em sociologia do esporte. São Paulo: Factash; 2011. p.55-73.

60. Souza J, Marchi Júnior W. Por uma gênese do campo da sociologia do esporte: cenários e perspetivas. Movimento (Porto Alegre). 2010;16:45-70.

61. Helal R. Futebol e comunicação: a consolidação do campo acadêmico no Brasil. Comun. Midia Consumo. 2011;8:11-37.

62. Souza JF. A construção social da subcidadania: para uma sociológica política da modernidade periférica. Belo Horizonte: UFMG; 2003.

63. Souza JF. A invisibilidade da desigualdade brasileira. Belo Horizonte: UFMG; 2006.

64. Souza JF. A ralé brasileira: quem é e como vive. Belo Horizonte: UFMG; 2009.

65. Souza JF. Os batalhadores brasileiros: nova classe média ou nova classe trabalhadora? Belo Horizonte: UFMG; 2010.

\begin{tabular}{|c|c|}
\hline $\begin{array}{r}\text { ENDEREÇo } \\
\text { Juliano de Souza } \\
\text { Centro de Pesquisas em Esporte, Lazer e Sociedade (CEPELS) } \\
\text { Departamento de Educação Física } \\
\text { Universidade Federal do Paraná } \\
\text { R. Coração de Maria, 92 - BR 116 - km 95 } \\
\text { 80215-370 - Curitiba - PR - BRASIL } \\
\text { e-mail: julianoedf@yahoo.com.br }\end{array}$ & $\begin{array}{l}\text { Recebido para publicação: 17/04/2013 } \\
\text { Revisado: 15/07/2013 } \\
\text { Aceito: 30/07/2013 }\end{array}$ \\
\hline
\end{tabular}

232 • Rev Bras Educ Fís Esporte, (São Paulo) 2014 Abr-Jun; 28(2):221-32 